\title{
A Multidisciplinary Approach to the Treatment of Gastric Cancer: What Is the Role of the Surgeon?
}

\author{
Abraham El-Sedfy ${ }^{1,2^{*}}$, Fadi Frankul ${ }^{1}$, Natalie G. Coburn ${ }^{1,3,4 \#}$ \\ ${ }^{1}$ Sunnybrook Research Institute, Toronto, Canada; ${ }^{2}$ Department of Surgery, Saint Barnabas Medical Center, Livingston, USA; \\ ${ }^{3}$ Department of Surgery, University of Toronto, Toronto, Canada; ${ }^{4}$ Division of Surgical Oncology, Odette Cancer Centre, Sunny- \\ brook Health Sciences Centre, Toronto, Canada. \\ Email:*elsedfa@gmail.com
}

Received July $30^{\text {th }}, 2013$; revised August $29^{\text {th }}, 2013$; accepted September $6^{\text {th }}, 2013$

Copyright (C) 2013 Abraham El-Sedfy et al. This is an open access article distributed under the Creative Commons Attribution License, which permits unrestricted use, distribution, and reproduction in any medium, provided the original work is properly cited.

\begin{abstract}
Despite recent declining incidence, gastric cancer remains one of the most common cancers worldwide. Its treatment involves a multidisciplinary team to ensure implementation of investigated pre-operative and post-operative treatment strategies to improve survival. Our aim is to discuss the current role of the surgeon in improving survival of gastric cancer patients.
\end{abstract}

Keywords: Gastric Cancer; Cancer Staging; Gastrectomy; Lymphadenectomy; Neo-Adjuvant Chemotherapy; Adjuvant Therapy; Chemoradiation

\section{Introduction}

Although the incidence of gastric cancer has declined, it still remains one of the most common causes of cancerrelated mortality worldwide [1,2]. Decreases of incidence in the West have been largely attributed to some improvements in primary prevention, including food storage, change in diet, lower consumption of salted and smoked foods, and a decrease in Helicobacter pylori infection rates $[3,4]$. However, late presentation of the disease is still common in the West and it results in presentation in advanced stages with lower survival. On the contrary, in the East, where the incidence of gastric cancer remains high, allowing for cost-effective population-based screening, better survival has been shown secondary to earlier detection $[5,6]$. Furthermore, the overall and stage-matched survival of resected patients is better in Eastern Asian series than those of North America [7]. Outcomes following resection vary widely with 5 -year survival rates ranging from $40 \%$ to $60 \%$ in series from Asia, but for similarly staged patients in North America, the 5-year survival rate approaches $30 \%[8,9]$. Differences in tumor biology, genetics, stage at presentation, location of tumor, the effects of stage migration, treatment and quality of surgical care are postulated to be reasons for this difference in survival $[8,9]$. However, surgery remains the

"Corresponding author.

\#Surgery and improving survival of gastric cancer. only modifiable factor.

Donabedian states that before assessment can be started, it is necessary to come to an agreement on elements that will help us to define quality of care [10]. Based on his theory, without a firm foundation and definition of quality of care, it is illogical to proceed to measurement [10]. Hence, the Donabedian model, a conceptual model providing guidelines for examining health services and evaluating quality of care, approaches assessment to quality of care by inferences drawn under three categories: "structure", "process", and "outcome" [10]. The concept of structure describes all the attributes of settings that affect the context in which care is delivered (i.e. resources, human resources, organizational structure) [10]. The concept of process entails the sum of all actions that are performed in giving and receiving health care (i.e. diagnosis, treatment, preventative care and patient education) [10]. Since process encompasses all acts of healthcare delivery, it is nearly equivalent to measurement of quality of care [10]. The concept of outcome represents the effects of health care delivered to patients on the changes to health status of those patients or populations [10]. The fundamental concept linking these three categories is the notion that good structure leads to good process and good process leads to good outcome [10]. Adequate staging, multidisciplinary care, optimal treatment planning, optimal surgical technique and provision 
of care in adequate facilities are structures and processes that are included in the treatment of gastric cancer.

Existing guidelines primarily address proper staging and multidisciplinary care; however do not fully address surgical technique and surgical decision making [11-15]. Studies have shown that outcomes are improved in patients undergoing gastrectomies from high-volume surgeons, which may be secondary to technical proficiency and intra-operative decision making process or patient selection and management [16]. Specifically, studies from The Netherlands have improved population-based outcomes for patients undergoing gastrectomies via the standardization of surgical technique [17]. This suggests that there is potential for quality improvement in surgery for gastric cancer through the establishment of appropriate and necessary processes of care for surgical management of gastric cancer patients [8]. Because surgery is a modifiable factor, this may also indicate that the role of surgery is not optimized and that there may be opportunities for surgeons to affect improvement in survival of gastric cancer patients. Our aim is to provide a comprehensive review of the current role of surgery in improving survival of gastric cancer patients.

\section{Appropriate Pre-Operative Staging}

The management and treatment of gastric cancer, being complex and resource intensive, requires decision-making and planning by a multidisciplinary team [18]. Once the diagnosis of gastric cancer is confirmed on esophagogastroduodenoscopy (EGD), accurate staging of tumor depth $(\mathrm{T})$, regional lymph node (LN) involvement $(\mathrm{N})$ and distant metastases $(\mathrm{M})$ are the key elements required for treatment planning. This clinical baseline stage provides clinicians with the information required to establish treatment strategies. Clinical staging accuracy has greatly improved, secondary to the availability of several diagnostic modalities for pre-operative evaluation of gastric cancer patients, including computed tomography (CT), magnetic resonance imaging (MRI), positron emission tomography (PET), endoscopic ultrasound (EUS) and staging laparoscopy [19-21]. Several published guidelines represent careful and systematic investigation of the latest literature resulting in rational, evidence based recommendations $[11,12,14,15]$.

It is believed that standardization of staging and preoperative workup may lead to improved outcomes by improving accuracy in pre-operative staging, resulting in a decrease of margin-positive resection rates, a decrease in unnecessary laparotomies and a decrease in peri-operative mortality $[18,22]$.

\subsection{Computed Tomography}

For the evaluation of local tumor and $\mathrm{LN}$ involvement, the presence of peritoneal dissemination and metastatic spread, necessary pre-treatment radiologic assessment should include a CT scan $[13,14,18]$. Kwee et al. (2007) performed a systematic review of $\mathrm{T}$ staging accuracy which revealed multi-detector CT (MDCT) scans had a T staging accuracy ranging from $77.1 \%$ to $88.9 \%$ [20]. Sensitivities and specificities for identification of serosal involvement varied between $82.8 \%$ to $100 \%$ and between $80 \%$ to $96.8 \%$ respectively [20]. Therefore, the Scottish Intercollegiate Guidelines Network (SIGN) (2006), the European Society Medical Oncology (ESMO) guidelines (2011), the United Kingdom National Health Service (NHS) Cancer Plan (2011) and the National Comprehensive Cancer Network (NCCN) guidelines (2013), recommend that patients diagnosed with gastric cancer should be pre-operatively evaluated with a CT abdomen with intravenous (IV) and oral (PO) contrast [12-15]. The four guidelines did not all agree on obtaining a pelvic CT preoperatively. Although the additional value of a pelvic $\mathrm{CT}$ has not been rigorously defined, as patients are at risk for pelvic peritoneal disease and ovarian metastasis in the female patients [13], the NHS guidelines recommend obtaining a pre-operative pelvic CT to evaluate for metastases, while the NCCN guidelines recommend obtaining a pelvic CT as clinically indicated $[12,14]$. Despite the incidence of lung metastases being low [23], a CT scan of the chest was considered an appropriate pre-operative evaluation by all four guidelines, especially in the setting of GEJ tumors [15].

\subsection{Positron Emission Tomography}

The pre-operative use of 18-F-Fluoro-2-deoxy-glucose (FDG) PET scans proved to be controversial amongst the four guidelines. Dassen et al. (2009) contend that there is no definite role for FDG-PET scans in the pre-operative evaluation of gastric cancer [24]. Studies revealed that FDG-PET is not accurate for detection of primary tumors because of the combination of low sensitivity and high specificity. Sensitivity rates from the studies performed range from $58 \%$ to $94 \%$, while the specificity rates range from $78 \%$ to $100 \%$ [24]. Dassen et al.'s (2009) review of the role of FDG-PET revealed that tumor location, tumor size and gastric cancer histological type are determinants that influenced sensitivity and specificity [24]. Sensitivities were higher for proximal lesions versus distal lesions. Sensitivities ranged from $26 \%$ to $63 \%$ for early gastric cancer (EGC), while it was $93 \%$ to $98 \%$ for locally advanced gastric cancer [24]. Furthermore, low sensitivities were shown for non-intestinal type gastric cancer [24]. While similar accuracy was noted between FDG-PET and CT scans for diagnosing local and distant lymph node metastases and peritoneal involvement, FDG-PET was found to have a lower sensitivity compared to $\mathrm{CT}$ scan in the detection of metastasis to lymph 
nodes (56\% vs $78 \%)$, but had improved specificity $(92 \%$ vs $62 \%$ ) [25]. In addition, combination PET-CT revealed more accurate staging than either modality alone (PET-CT vs. CT alone: $66 \%$ vs $51 \%$; PET-CT vs PET alone: $66 \%$ vs $47 \% ; \mathrm{P}=0.002$ ) [25]. It is interesting to note that SIGN guidelines, published earliest amongst the four mentioned guidelines, do not advocate the routine use of PET scans in the staging of gastric cancer [13]. ESMO and NHS recommend FDG-PET or PET-CT for specific patients with proximal tumors near the GEJ [14, 15]. The NCCN guidelines recommend a PET-CT if there is no evidence of M1 disease on CT evaluation and state that it is not appropriate for $\mathrm{T} 1$ patients [12]. Whereas, an international expert panel from a RAND/ UCLA Appropriateness Method (RAM) study defining processes of care in the optimal management of gastric cancer, concluded that PET scans are not routinely indicated in staging because their utility in changing management has not yet been defined [26].

\subsection{Endoscopic Ultrasound}

Endoscopic ultrasound (EUS) has become an available mode of pre-operative staging of gastric cancer [27]. While some guidelines advocate the use of EUS, others do not, as its utility remains unclear in the routine preoperative evaluation/staging of gastric cancer. Evaluation of the individual layers of the gastric wall can be evaluated by EUS [27], however its lack of unanimous support by experts may be because EUS often does not change management strategies for resectable tumors by radiologic staging, unless there is anticipation for an endoscopic resection [18]. The SIGN guidelines recommend an EUS for patients with GEJ tumors who are candidates for curative resection [13]. ESMO guidelines have not provided a complete consensus on the application of EUS, however maintain that there may be a role to guide pre-operative treatment for certain patients with superficial disease or with linitis plastica [15]. NHS guidelines recommend an EUS for patients with GEJ tumors [14]. NCCN guidelines recommend that an EUS is indicated for assessing the depth of tumor invasion and if there is no evidence of M1 disease [12].

\subsection{Laparoscopy}

A highly accurate modality for identification of metastatic spread is laparoscopy [22,28-30]. Diagnostic laparoscopy for staging of gastric cancer should include the inspection of the stomach, diaphragm, liver and ovaries [18,31]. Sarela et al. (2006) evaluated 657 patients with potentially resectable gastric cancer over a 10 year period and discovered that $31 \%$ had M1 disease [30]. The SIGN guidelines indicate that laparoscopy should be considered in patients with suspected full thickness gastric wall tumor involvement [13]. ESMO recommends performing a staging laparoscopy, however there was no consensus on performing a peritoneal lavage because of the varying implications on therapy [15]. NHS recommend performing a laparoscopy in all patients with gastric cancer, and NCCN guidelines recommend that laparoscopy was deemed a necessary pre-operative maneuver for patients considered for surgical resection without pre-operative therapy and in patients with suspected T3 or T4 tumors [12]. NCCN guidelines also state that laparoscopy with cytology of peritoneal washings was recommended for patients for whom pre-operative therapy was planned [12].

\section{Surgical Treatment of Gastric Cancer}

Curative treatment of gastric cancer requires surgical resection. Four approaches are utilized for curative treatment of localized gastric cancer: endoscopic mucosal resection (EMR) or endoscopic submucosal dissection (ESD), minimally invasive approach and open approach [32].

\subsection{Endoscopic Approaches}

Gastric cancer diagnosed in early stages and confined to the mucosa or submucosa is believed to have a very low risk of lymph node metastasis. In Japan, the standard indication for the treatment of EGC by EMR includes well differentiated tumors, measuring less than $2 \mathrm{~cm}$ in size, and with no submucosal involvement or lymphangio invasion [33]. Although no RCTs exist comparing endoscopic resections with formal surgical resections [34], cohort studies have revealed that EMR treated patients had 5 and 10 year disease-specific survival of greater than $95 \%$ ( $99 \%$ at 5 years) with an incidence of recurrence of approximately 5.8\% [35]. In addition, these studies revealed that endoscopic approaches had favorable complication rates compared to formal surgical resections [35].

ESD in comparison with EMR can be utilized on larger EGC and more frequently allows practitioners to remove the tumor in one piece $(92.7 \%$ vs $56 \%)$ [36,37]. Oda et al. (2006), in their retrospective multicenter study, revealed that the 3-year recurrence free rate was higher with ESD than EMR (97.6\% vs $92.5 \%$ respectively), however this proved to be associated with higher perforation rates (3.6\% vs $1.2 \%$ respectively) [37]. Therefore, according to the Japanese Gastric Cancer Association (JGCA) guidelines, ESD is performed for well differentiated intra-mucosal (T1a) tumors only [38].

\subsection{Laparoscopic Approach}

A laparoscopic approach to treatment of EGC and distal gastric cancer has been performed mainly in Korea and 
Japan since 1991 [32,38]. Surgeon experience with laparoscopy is increasing and there have been great technological advancements in instrumentation over the years. There exist several, mostly single-center, RCT that have been published comparing laparoscopic to open gastric resection conducted mainly in patients with EGC [3942]. These studies have favorably supported laparoscopic gastric resections for early stage gastric cancer [43-45]. The laparoscopic approach has shown benefits when compared to an open approach with respect to short-term results, including reduced operative blood loss, less postoperative pain and earlier discharge from hospital [4345]. A meta-analysis study of the RCTs also revealed the laparoscopic group had quicker return of bowel function (earlier first flatus and earlier food intake), but longer operative times and less harvested lymph nodes [46]. There was no significant difference in tumor recurrence between the two groups, although this outcome was not measured in all RCTs [46].

EGC (T1/T2, N0) is considered the only indication for laparoscopic gastrectomy in Japan. Level one data presented provides evidence supporting laparoscopic resection for gastric cancer as a technically safe procedure with some short-term outcome improvements (i.e. duration of hospitalization, pain control, blood loss, cosmesis), however large multi-center RCTs are necessary to establish the long-term oncological outcome supporting laparoscopic resection in the treatment of advanced gastric cancer [47,48]. Two groups, the Japan Clinical Oncology Group (JCOG 0912 study) and the Korean Laparoscopic Gastrointestinal Surgery Study (KLASS) Group (KLASS 01 Study), have initiated large multicenter RCT comparing laparoscopic gastrectomy with open gastrectomy $[49,50]$. In addition, the KLASS group is also performing a separate phase III study (KLASS 02 Study) to evaluate the efficacy of laparoscopic resection in advanced gastric cancer patients [49].

\subsection{Surgical Gastric Resection and Margins}

Theodor Billroth performed the first successful resection for gastric cancer in 1881 and since then, surgery remains the only curative treatment for this disease [8]. Following staging, treatment plans are discussed in a multi-disciplinary forum and the surgeon then has the potential to influence survival outcomes by performing an adequate surgical resection [51]. A fundamental concept to surgical oncology is the complete removal of cancer without residual microscopic or macroscopic disease [8]. Therefore, this involves negative (R0) margins, an omentectomy and an adequate lymphadenectomy [51].

In order to achieve negative margins, the type of operation performed depends on both the location and the stage of the tumor [8]. Proximal or middle third of stomach tumors are treated with a proximal or total gastrec- tomy [52]. However, proximal gastrectomy is rarely performed as there is an association with markedly higher rates of complications including anastomotic stenosis, reflux esophagitis and no change in nutritional status in comparison to total gastrectomies [53]. For distal tumors, a subtotal distal gastrectomy should be performed as Gouzi et al. (1989) and Bozzetti et al. (1999) performed two large separate RCTs that showed no difference in overall survival, but decreased morbidity, when compared with the more extensive total gastrectomy $[54,55]$. Therefore, total gastrectomies should be avoided in distal lesions unless necessary to achieve negative margins [51].

Although series have shown that R0 resections confer better survival, the rate of positive margins has been reported as high as $20 \%$ [56]. Incomplete surgical removal of tumor is associated with markedly worse survival [56]. Bozetti et al. (1982) have suggested that a minimum of $6 \mathrm{~cm}$ grossly negative margin be resected to ensure a microscopically negative margin [57]. However, due to the difficulty in uniformly achieving an R0 margin, some authors suggest routinely performing frozen section analysis for potentially curative resections [32].

The decision to perform re-resection of positive margins was recognized as difficult, and should be individualized, based on patient and tumor factors [58]. While positive margins are more common in advanced stage cases, patients with advanced gastric cancer are thought to be less likely adversely affected by positive margins because their risk of recurrence or metastatic disease is higher [8]. Data suggests that the greatest benefit to reresection occurs in earlier stage patients. Therefore, several authors have advocated multi-visceral resection or re-resection on in patients with $<5$ LNs positive [56, 59]. However, Chen et al. (2012) recommend obtaining routine frozen sections of all gastric cancer patients undergoing potentially curative resection, especially in those patients with $\leq \mathrm{N} 2$ disease and those undergoing D2 lymphadenectomy [60]. They showed that the re-excision of a positive margin in patients with advanced gastric cancer improved median survival overall from 18 months to 23 months $(\mathrm{P}=0.019)$ and specifically for patients with $\leq \mathrm{N} 2$ disease showed an improvement in median survival from 25 months to 44 months $(\mathrm{P}=0.021)$ [60].

Furthermore, Brar et al. (2013) performed a RAND/ UCLA Appropriateness Methodology (RAM) study consisting of an expert panel to help determine which patient set may benefit from a frozen section to establish negative margins [8]. The expert panel stated that it is appropriate to perform an intra-operative assessment of the proximal margin if the gross margin is $<5 \mathrm{~cm}$, or if the tumor is T3 or T4 [8]. Further, for positive proximal margins on frozen section for N0 and M0 patients, it was necessary to perform re-resection of the stomach and/or 
abdominal esophagus; and appropriate, but not necessary, for re-resection of the thoracic esophagus [8]. For positive proximal margins on frozen section for $\mathrm{N} 1$ and $\mathrm{M} 0$, that it was deemed appropriate, but not necessary, to perform re-resection of the stomach, abdominal and/or thoracic esophagus [8]. For N2 to N3 disease and M0, the expert panel concluded that it was appropriate to conduct re-resection of the stomach and/or abdominal esophagus, but not the thoracic esophagus [8]. Thus, the need to re-resect is based upon the biology of the disease, as well as the location of the margin.

\subsection{Adequate Lymphadenectomy}

The extent of lymphadenectomy has been a controversial issue in determining adequate surgical resection of gastric cancer. A D1 lymphadenectomy entails the dissection of LNs adjacent to the stomach. A D2 lymphadenectomy, in addition to the LNs surrounding the stomach, also includes the dissection of LNs around the branches of the celiac axis, while a D3 lymphadenectomy includes removal of para-aortic LNs. Non-randomized studies from Asia, Europe and North America have reported improved survival in the more extensive D2 lymphadenectomy [61-64], yet many surgeons continue to perform a D1 lymphadenectomy. Two RCTs have failed to demonstrate a 5-year survival benefit for performing a D2 lymphadenectomy over a D1 lymphadenectomy, but instead revealed a higher complication rate $[65,66]$. Criticism of these studies include that dissections were performed by low volume surgeons and that they resected the tail of the pancreas and spleen, which is no longer recommended as standard of care during a D2 lymphadenectomy, and may have led to excess morbidity $[65,66]$.

More recently, follow up of the Dutch trial reported that a D2 lymphadenectomy was associated with lower locoregional recurrence and improved disease-specific survival [67]. Songun et al. (2010) also recommended spleen-preserving D2 resection as the standard operative choice for resectable gastric cancer at high-volume specialized centers [67]. Degiuli et al. (2004) have shown that there was no significant difference in morbidity and mortality between D1 and D2 lymphadenectomies and recommended a $\mathrm{D} 2$ resection as the operative choice in Western specialized centers, however long-term survival results are still pending [61].

D3 lymphadenectomy or para-aortic LN dissection was attempted in the past in hope of improving survival rates in patients with advanced gastric cancer. However, a prospective randomized study from Japan (JCOG study 9501) failed to demonstrate a survival benefit for paraaortic (D3) lymphadenectomy over D2 alone [68,69].

Guidelines recently published in the United States, United Kingdom and Europe recommend performing a D2 lymphadenectomy for curative-intent resection in advanced, non-metastatic gastric cancer by high-volume surgeons [12-14]. JGCA guidelines recommend that a D2 lymphadenectomy be performed for potentially curable $\mathrm{T} 2$ to $\mathrm{T} 4$ tumors and $\mathrm{T} 1 \mathrm{~N}+$ patients [11]. D1 lymphadenectomy resection may be preferred for patients with EGC or in patients with advanced disease, but who also have substantial co-morbidities [12-14].

Although there is a debate on the type of lymph node resection, there is agreement about the number of LNs required for adequate staging of gastric cancer patients. In accordance with the American Joint Commission on Cancer (AJCC) TNM staging, it was appropriate and necessary to assess at least 16 LNs [8]. Although it has been widely recognized that a minimum number of LNs are required for adequate staging, numerous studies have shown that this minimum is rarely achieved in the United States, and with considerable regional variation, and improved survival associated with appropriate staging [7072].

The Maruyama Index (MI) of Unresected Disease is another method for assessing adequacy of $\mathrm{LN}$ removal established by a computer-generated likelihood of nodal involvement for each regional LN station left in situ [73]. To determine the probability of residual disease, this assessment is performed by matching a case with similar cases, from a database of nearly 5000 patients, previously treated at the National Cancer Center Hospital in Tokyo [73]. Secondary analysis of Intergroup 0116 trial and the Dutch RCT trial revealed an overall survival (OS) benefit with lower MI [73]. OS improved to 87 months from 27 months $(\mathrm{P}=0.005)$ in the Intergroup 0116 trial patients with $\mathrm{MI}<5$ compared to those with an $\mathrm{MI} \geq 5$ [73]. In addition, patients with $\mathrm{MI}<5$ had improved median disease-free survival (DFS) of 87 months from 20 months when compared to those with an $\mathrm{MI} \geq 5$ [73]. MI proved to be an independent predictor of survival on multi-variate analysis. With T, N and treatment group as co-variates, the hazard ratio (HR) was 1.9 for OS [95\% confidence interval (CI) $1.3-2.8$ ] and 2.0 DFS (95\% CI 1.4 - 2.9) [73]. On secondary analysis of the Dutch trial, MI $<5$ revealed an OS HR of 1.45 (95\% CI $1.07-1.95)$ and a DFS HR of 1.73 (95\% CI 1.14 - 2.60) [73]. Intergroup 0116 trial and Dutch RCT patients had median MI of 70 and 26, respectively [73]. The $\mathrm{T}$ and $\mathrm{N}$ stage of a patient cannot be modified once in the operating room, however the surgeon has the ability to modify the resection to achieve an $\mathrm{MI}<5$.

\subsection{Bursectomy}

Although recommended by the JGCA Guidelines for advanced gastric cancer [11], the bursectomy, which is dissection of the peritoneal lining covering the pancreas and the anterior leaf of the transverse mesocolon, had fallen out of favor until a recent publication by Fujita et 
al. (2012) [74]. Although under-powered due to early closure, their study comparing D2 gastrectomy with or without bursectomy in patients with $\mathrm{T} 2$ or $\mathrm{T} 3$ gastric cancer showed no difference in overall morbidity or mortality between the two groups, but a 3-year OS of $85.6 \%$ in the bursectomy group in comparison to $79.6 \%$ in the non-bursectomy group [74]. It is interesting to note, that in 48 serosa positive patients there was a greater improvement in 3-year OS between the bursectomy group and the non-bursectomy group $(69.8 \%$ vs $50.2 \%$, respectively) and a decrease in peritoneal recurrences in the bursectomy group $(8.7 \%)$ in comparison to the nonbursectomy group (13.2\%) [74]. More definitive results from the larger JCOG study 1001 evaluating the benefit of bursectomies in patients with clinical T3 and T4 tumors is still pending.

\subsection{Surgical Management of Stage IV Disease}

In countries with a low incidence of gastric cancer, the majority of patients present with advanced stage disease that is not amenable to curative resection [75]. There has been much debate in the surgical literature regarding the role of non-curative resection. A non-curative gastrectomy may be useful only in a minority of patients with Stage IV disease and therefore must be performed judiciously [51], as complication rates for non-curative surgery (resections and bypass) in this group of patients are high. While there may be an improvement on median survival in comparison to chemotherapy alone, this is likely secondary to large selection bias [76]. As there may be a select subset of patients with advanced cancer who may benefit from a non-curative gastrectomy [76], two trials have been initiated. The GYMSSA (GastrecomY and Metastectomy plus Systemic therapy vs Systemic therapy Alone) and REGATTA (REductive Gastrectomy for Advance Tumor in Two Asian countries) trials will evaluate the survival benefit and adverse events associated with gastrectomy with metastectomy and systemic therapy in comparison to systemic therapy alone in patients with metastatic disease $[77,78]$. These two trials aim to identify patient selection factors for performing gastrectomies in patients with limited metastasis $[77,78]$.

Currently, in the setting of metastasis, NCCN guidelines state that a gastric resection is to be performed only for palliation of symptoms (i.e. obstruction or bleeding) [12]. Furthermore, an international expert panel from a RAM study defining processes of care in the optimal management of gastric cancer, concluded that in the setting of metastasis, to consider surgical resection only for palliation of major symptoms [26]. Therefore at this point in time, less invasive alternatives should be employed to alleviate symptoms and improve quality of life such as stenting, radiation, embolization and chemo- therapy alone [51]. Surgery should be performed only once the burden of disease, likelihood of complications and the availability of other treatment modalities have been weighed against the severity of the patient's symptoms [79].

\section{Adjuvant Therapies}

Despite curative-intent surgery, there is a high chance of recurrent disease, therefore adjunctive therapies of gastric cancer resection have become of interest to improve survival [80]. The addition of peri-operative chemotherapy or adjuvant chemo-radiation has been shown in randomized controlled trials to improve survival [80]. Highlighting the need to consider gastric cancer as a multi-modality treated disease, MacDonald et al. (2001) revealed that adjuvant chemo-radiation improved median survival from 27 to 36 months $(P=0.005)$ [81], while Cunningham et al. (2006) showed that peri-operative chemotherapy improved overall survival from 23\% to $36 \%$ at 5 years $(\mathrm{P}=0.008)$ [82].

There have also been numerous RCTs performed comparing surgery alone with adjuvant chemotherapy, however we have yet to standardize therapy based on the varying evidence. The GASTRIC Group (Global Advanced/Adjuvant Stomach Tumor Research International Collaboration) performed an individual patient-level meta-analysis of all RCTs to evaluate the potential benefit of gastrectomy with adjuvant chemotherapy in comparison to surgery alone [83]. In this meta-analysis, they identified 31 RCTs in total, but analyzed 17 trials with 3838 patients with a median follow-up greater than 7 years, as certain trials were excluded with the use of radiotherapy, neoadjuvant, perioperative or intra-peritoneal chemotherapy or immunotherapy [83]. RCTs of four groups of regimens were identified 1) monochemotherapy agents; 2) fluorouracil, mitomycin C, and other therapies without anthracyclines; 3) fluorouracil, mitomycin $\mathrm{C}$, and anthracyclines; and 4) other polychemotherapy regimens and endpoint measurements included OS and DFS [83]. In the adjuvant chemotherapy group of patients, The GASTRIC Group was able to demonstrate statistically significant improvements in the OS (HR 0.82; 95\% CI $0.76-0.90 ; \mathrm{P}<0.001$ ) and DFS (HR 0.82; 95\% CI $0.75-0.90 ; \mathrm{P}<0.001$ ) [83]. They did not demonstrate significant heterogeneity for OS across the RCTs or the 4 chemotherapy regimen groups, however they demonstrated that adjuvant chemotherapy increased 5-year OS from $49.6 \%$ to $55.3 \%$ [83].

Following the publication of ACTS-GS trial (Adjuvant Chemotherapy Trial of S-1 for Gastric Cancer) results in 2007, adjuvant chemotherapy S-1 for 1 year without radiation has recently become the standard of care in Japan following a D2 Gastrectomy [83,84]. The ACTSGS trial results demonstrated improved OS, low inci- 
dence of adverse events and good patient compliance, but less than satisfactory OS rates for stage III patients [84]. Takahiri et al. (2013) demonstrated promising efficacy for stage III gastric cancer when post-operative patients are treated with 3 cycles of cisplatin in addition to S-1 [84]. The CLASSIC trial (Capecitabine and Oxaliplatin Adjuvant Study in Stomach Cancer), performed in 37 centers across South Korea, China and Taiwan, demonstrated an improvement in 3-year disease-free survival when adjuvant capecitabine plus oxaliplatin chemotherapy regimen was implemented after D2 gastrectomy in comparison to surgery alone $[74 \%(95 \%$ CI 69 - 79) vs $59 \%(53-64)]$ [85]. When comparing the three pivotal trials of adjuvant and neoadjuvant therapy, Sano (2008) stated that "The East and West have different patient populations and surgical approaches with different baseline survival rates; therefore, despite some cross-over, their studies are likely to move forward in separate directions" [86]. Thus, underscoring the need for a preoperative multi-disciplinary discussion to ensure that all options of neoadjuvant or adjuvant therapy regimens are considered and evaluated.

\section{Conclusions}

Establishment of uniformity and identification of appropriate and necessary practices in the pre-operative management of gastric cancer is vital to ensure accurate staging and adequate treatment. Importantly, accurate preoperative radiographic and laparoscopic staging allows us to stratify patients into optimal stage-specific treatments and therefore improve survival outcomes. It allows us to select which patients may benefit from surgical resection versus those patients who would not benefit from invasive procedures.

The surgical resection of gastric cancer includes either endoscopic, laparoscopic or open approaches. EMR and ESD have shown favorable results for the limited resections of EGC. In addition, laparoscopy has proven to benefit for short term results in EGC, but long term outcomes are pending. A fundamental concept of oncological gastric surgery is to obtain an $\mathrm{R} 0$ resection with an adequate lymphadenectomy. In the setting of metastasis, selecting patients may benefit from a gastric resection, however, results from large trials are still pending. Finally, studies have concluded that gastric cancer patients should be considered for adjuvant therapy, highlighting that the management and treatment of gastric cancer require a multi-disciplinary approach.

\section{REFERENCES}

[1] J. Ferlay, H. R. Shin, F. Bray, D. Forman, C. Mathers and D. M. Parkin, "Estimates of Worldwide Burden of Cancer in 2008: GLOBOCAN 2008," International Journal of
Cancer, Vol. 127, No. 12, 2010, pp. 2893-2917. http://dx.doi.org/10.1002/ijc.25516

[2] R. Siegel, D. Naishadham and A. Jemal, "Cancer Statistics, 2013," CA: A Cancer Journal for Clinicians, Vol. 63, No. 1, 2013, pp. 11-30. http://dx.doi.org/10.3322/caac.21166

[3] C. de Martel, D. Forman and M. Plummer, "Gastric Cancer: Epidemiology and Risk Factors," Gastroenterology Clinics of North America, Vol. 42, No. 2, 2013, pp. 219240. http://dx.doi.org/10.1016/j.gtc.2013.01.003

[4] W. Demark-Wahnefried, C. L. Rock, K. Patrick and T. Byers, "Lifestyle Interventions to Reduce Cancer Risk and Improve Outcomes," American Family Physician, Vol. 77, No. 11, 2008, pp. 1573-1578.

[5] K. W. Jung, S. Park, H. J. Kong, Y. J. Won, J. Y. Lee, E. C. Park and J. S. Lee, "Cancer Statistics in Korea: Incidence, Mortality, Survival, and Prevalence in 2008," Cancer Research and Treatment, Vol. 43, No. 1, 2011, pp. 1-11. http://dx.doi.org/10.4143/crt.2011.43.1.1

[6] J. L. Whiting, A. Sigurdsson, D. C. Rowlands, M. T. Hallissey and J. W. Fielding, "The Long Term Results of Endoscopic Surveillance of Premalignant Gastric Lesions," Gut, Vol. 50, No. 3, 2002, pp. 378-381. http://dx.doi.org/10.1136/gut.50.3.378

[7] V. E. Strong, K. Y. Song, C. H. Park, L. M. Jacks, M. Gonen, M. Shah, D. G. Coit and M. F. Brennan, "Comparison of Gastric Cancer Survival Following R0 Resection in the United States and Korea Using an Internationally Validated Nomogram," Annals of Surgery, Vol. 251, No. 4, 2010, pp. 640-646.

http://dx.doi.org/10.1097/SLA.0b013e3181d3d29b

[8] S. Brar, C. Law, R. McLeod, L. Helyer, C. Swallow, L. Paszat, R. Seevaratnam, R. Cardoso, M. Dixon, A. Mahar, L. G. Lourenco, L. Yohanathan, A. Bocicariu, T. BekaiiSaab, I. Chau, N. Church, D. Coit, C. H. Crane, C. Earle, P. Mansfield, N. Marcon, T. Miner, S. H. Noh, G. Porter, M. C. Posner, V. Prachand, T. Sano, C. van de Velde, S. Wong and N. Coburn, "Defining Surgical Quality in Gastric Cancer: A RAND/UCLA Appropriateness Study," Journal of the American College of Surgeons, Vol. 215, No. 2, 2013, pp. 347-357. http://dx.doi.org/10.1016/j.jamcollsurg.2013.01.067

[9] N. G. Coburn, L. G. Lourenco, S. E. Rossi, N. Gunraj, A. L. Mahar, L. K. Helyer, C. Law, L. Rabeneck and L. Paszat, "Management of Gastric Cancer in Ontario," Journal of Surgical Oncology, Vol. 102, No. 1, 2010, pp. 54-63. http://dx.doi.org/10.1002/jso.21561

[10] A. Donabedian, "The quality of Care. How Can It Be Assessed?" The Journal of the American Medical Association, Vol. 260, No. 12, 1988, pp. 1743-1748. http://dx.doi.org/10.1001/jama.1988.03410120089033

[11] Japanese Gastric Cancer Association, "Japanese Gastric Cancer Treatment Guidelines 2010 (Version 3)," Gastric Cancer, Vol. 14, No. 2, 2011, pp. 113-123. http://dx.doi.org/10.1007/s10120-011-0042-4

[12] J. A. Ajani, D. J. Bentrem, S. Besh, T. A. D'Amico, P. Das, C. Denlinger, M. G. Fakih, C. S. Fuchs, H. Gerdes, R. E. Glasgow, J. A. Hayman, W. L. Hofstetter, D. H. Ilson, R. N. Keswani, L. R. Kleinberg, W. M. Korn, A. C. 
Lockhart, K. Meredith, M. F. Mulcahy, M. B. Orringer, J. A. Posey, A. R. Sasson, W. J. Scott, V. E. Strong, T. K. Varghese Jr., G. Warren, M. K. Washington, C. Willett, C. D. Wright, N. R. McMillian and H. Sundar, "Gastric Cancer, Version 2. 2013: Featured Updates to the NCCN Guidelines," Journal of the National Comprehensive Cancer Network, Vol. 11, No. 5, 2013, pp. 531-546.

[13] D. Alderson, "Scottish Intercollegiate Guidelines Network (SIGN) 87-The Management of Oesophageal and Gastric Cancer," Clinical Oncology (Royal College of Radiologists), Vol. 20, No. 7, 2008, pp. 530-531. http://dx.doi.org/10.1016/j.clon.2008.04.015

[14] W. H. Allum, J. M. Blazeby, S. M. Griffin, D. Cunningham, J. A. Jankowski and R. Wong, "Guidelines for the Management of Oesophageal and Gastric Cancer," Gut, Vol. 60, No. 11, 2011, pp. 1449-1472.

http://dx.doi.org/10.1136/gut.2010.228254

[15] E. Van Cutsem, M. Dicato, R. Geva, N. Arber, Y. Bang, A. Benson, A. Cervantes, E. Diaz-Rubio, M. Ducreux, R. Glynne-Jones, A. Grothey, D. Haller, K. Haustermans, D. Kerr, B. Nordlinger, J. Marshall, B. D. Minsky, Y. K. Kang, R. Labianca, F. Lordick, A. Ohtsu, N. Pavlidis, A. Roth, P. Rougier, H. J. Schmoll, A. Sobrero, J. Tabernero, C. Van de Velde and J. Zalcberg, "The Diagnosis and Management of Gastric Cancer: Expert Discussion and Recommendations from the 12th ESMO/World Congress on Gastrointestinal Cancer, Barcelona, 2010," Annals of Oncology, Vol. 22, Supplement 5, 2011, pp. v1-v9. http://dx.doi.org/10.1093/annonc/mdr284

[16] J. D. Birkmeyer, Y. Sun, A. Goldfaden, N. J. Birkmeyer and T. A. Stukel, "Volume and Process of Care in HighRisk Cancer Surgery," Cancer, Vol. 106, No. 11, 2006, pp. 2476-2481. http://dx.doi.org/10.1002/cncr.21888

[17] P. Krijnen, M. den Dulk, E. Meershoek-Klein Kranenbarg, M. L. Jansen-Landheer and C. J. van de Velde, "Improved Survival after Resectable Non-Cardia Gastric Cancer in the Netherlands: The Importance of Surgical Training and Quality Control," European Journal of Surgical Oncology, Vol. 35, No. 7, 2009, pp. 715-720. http://dx.doi.org/10.1016/j.ejso.2008.12.008

[18] M. Dixon, R. Cardoso, J. Tinmouth, L. Helyer, C. Law, C. Swallow, L. Paszat, R. McLeod, R. Seevaratnam, A. Mahar and N. G. Coburn, "What Studies Are Appropriate and Necessary for Staging Gastric Adenocarcinoma? Results of an International RAND/UCLA Expert Panel," Gastric Cancer, Epub Ahead of Print, 2013. http://dx.doi.org/10.1007/s10120-013-0262-x

[19] E. K. Abdalla and P. W. Pisters, "Staging and Preoperative Evaluation of Upper Gastrointestinal Malignancies," Seminars in Oncology, Vol. 31, No. 4, 2004, pp. 513-529. http://dx.doi.org/10.1053/j.seminoncol.2004.04.014

[20] R. M. Kwee and T. C. Kwee, "Imaging in Local Staging of Gastric Cancer: A Systematic Review," Journal of Clinical Oncology, Vol. 25, No. 15, 2007, pp. 2107-2116. http://dx.doi.org/10.1200/JCO.2006.09.5224

[21] W. A. Weber and K. Ott, "Imaging of Esophageal and Gastric Cancer," Seminars in Oncology, Vol. 31, No. 4, 2004, pp. 530-541. http://dx.doi.org/10.1053/j.seminoncol.2004.04.016
[22] B. R. Smith and B. E. Stabile, "Gastric Adenocarcinoma: Reduction of Perioperative Mortality by Avoidance of Nontherapeutic Laparotomy," Journal of Gastrointestinal Surgery, Vol. 11, No. 2, 2007: pp. 127-132. http://dx.doi.org/10.1007/s11605-006-0019-5

[23] C. D. Kemp, M. Kitano, S. Kerkar, R. T. Ripley, J. U. Marquardt, D. S. Schrump and I. Avital, "Pulmonary Resection for Metastatic Gastric Cancer," Journal of Thoracic Oncology, Vol. 5, No. 11, 2010, pp. 1796-1805. http://dx.doi.org/10.1097/JTO.0b013e3181ed3514

[24] A. E. Dassen, D. J. Lips, C. J. Hoekstra, J. F. Pruijt and K. Bosscha, "FDG-PET Has No Definite Role in Preoperative Imaging in Gastric Cancer," European Journal of Surgical Oncology, Vol. 35, No. 5, 2009, pp. 449-455. http://dx.doi.org/10.1016/j.ejso.2008.11.010

[25] J. Chen, J. H. Cheong, M. J. Yun, J. Kim, J. S. Lim, W. J. Hyung and S. H. Noh, "Improvement in Preoperative Staging of Gastric Adenocarcinoma with Positron Emission Tomography," Cancer, Vol. 103, No. 11, 2005, pp. 2383-2390. http://dx.doi.org/10.1002/cncr.21074

[26] N. Coburn, R. Seevaratnam, L. Paszat, L. Helyer, C. Law, C. Swallow, R. Cardosa, A. Mahar, L. G. Lourenco, M. Dixon, T. Bekaii-Saab, I. Chau, N. Church, D. Coit, C. H. Crane, C. Earle, P. Mansfield, N. Marcon, T. Miner, S. H. Noh, G. Porter, M. C. Posner, V. Prachand, T. Sano, C. van de Velde, S. Wong and R. McLeod, "Optimal Management of Gastric Cancer: Results From an International RAND/UCLA Expert Panel," Annals of Surgery, Epub Ahead of Print, 2013. http://dx.doi.org/10.1097/SLA.0b013e318288dd2b

[27] S. R. Puli, J. Batapati Krishna Reddy, M. L. Bechtold, M. R. Antillon and J. A. Ibdah, "How Good Is Endoscopic Ultrasound for TNM Staging of Gastric Cancers? A Meta-Analysis and Systematic Review," World Journal of Gastroenterology, Vol. 14, No. 25, 2008, pp. 40114019. http://dx.doi.org/10.3748/wjg.14.4011

[28] E. C. Burke, M. S. Karpeh, K. C. Conlon and M. F. Brennan, "Laparoscopy in the Management of Gastric Adenocarcinoma," Annals of Surgery, Vol. 225, No. 3, 1997, pp. 262-267. http://dx.doi.org/10.1097/00000658-199703000-00004

[29] P. A. Leake, R. Cardoso, R. Seevaratnam, L. Lourenco, L. Helyer, A. Mahar, C. Law and N. G. Coburn, "A Systematic Review of the Accuracy and Indications for Diagnostic Laparoscopy Prior to Curative-Intent Resection of Gastric Cancer," Gastric Cancer, Vol. 15 Supplement 1, 2012, pp. S38-S47. http://dx.doi.org/10.1007/s10120-011-0047-z

[30] A. I. Sarela, R. Lefkowitz, M. F. Brennan and M. S. Karpeh, "Selection of Patients with Gastric Adenocarcinoma for Laparoscopic Staging," The American Journal of Surgery, Vol. 191, No. 1, 2006, pp. 134-138. http://dx.doi.org/10.1016/j.amjsurg.2005.10.015

[31] D. M. D’Ugo, V. Pende, R. Persiani, S. Rausei and A. Picciocchi, "Laparoscopic Staging of Gastric Cancer: An Overview," Journal of the American College of Surgeons, Vol. 196, No. 6, 2003, pp. 965-974. http://dx.doi.org/10.1016/S1072-7515(03)00126-1

[32] J. L. Dikken, C. J. van de Velde, D. G. Coit, M. A. Shah, 
M. Verheij and A. Cats, "Treatment of Resectable Gastric Cancer," Therapeutic Advances in Gastroenterology, Vol. 5, No. 1, 2012, pp. 49-69. http://dx.doi.org/10.1177/1756283X11410771

[33] T. Nakajima, "Gastric Cancer Treatment Guidelines in Japan,” Gastric Cancer, Vol. 5, No. 1, 2002, pp. 1-5. http://dx.doi.org/10.1007/s101200200000

[34] Y. P. Wang, C. Bennett and T. Pan, "Endoscopic Mucosal Resection for Early Gastric Cancer," Cochrane Database of Systematic Reviews, No. 1, 2006, Article ID: CD004276.

[35] S. G. Kim, "Endoscopic Treatment for Early Gastric Cancer," Journal of Gastric Cancer, Vol. 11, No. 3, 2011, pp. 146-154. http://dx.doi.org/10.5230/jgc.2011.11.3.146

[36] T. Gotoda, H. Yamamoto and R. M. Soetikno, "Endoscopic Submucosal Dissection of Early Gastric Cancer," Journal of Gastroenterology, Vol. 41, No. 10, 2006, pp. 929-942. http://dx.doi.org/10.1007/s00535-006-1954-3

[37] I. Oda, D. Saito, M. Tada, H. Iishi, S. Tanabe, T. Oyama, T. Doi, Y. Otani, J. Fujisaki, Y. Ajioka, T. Hamada, H. Inoue, T. Gotoda and S. Yoshida, "A Multicenter Retrospective Study of Endoscopic Resection for Early Gastric Cancer," Gastric Cancer, Vol. 9, No. 4, 2006, pp. 262270. http://dx.doi.org/10.1007/s10120-006-0389-0

[38] H. H. Hartgrink, E. P. Jansen, N. C. van Grieken and C. J. van de Velde, "Gastric Cancer," The Lancet, Vol. 374, No. 9688, 2009, pp. 477-490. http://dx.doi.org/10.1016/S0140-6736(09)60617-6

[39] H. Hayashi, T. Ochiai, H. Shimada and Y. Gunji, "Prospective Randomized Study of Open versus LaparoscopyAssisted Distal Gastrectomy with Extraperigastric Lymph Node Dissection for Early Gastric Cancer," Surgical Endoscopy And Other Interventional Techniques, Vol. 19, No. 9, 2005, pp. 1172-1176. http://dx.doi.org/10.1007/s00464-004-8207-4

[40] C. G. Huscher, A. Mingoli, G. Sgarzini, A. Sansonetti, M. Di Paola, A. Recher and C. Ponzano, "Laparoscopic versus Open Subtotal Gastrectomy for Distal Gastric Cancer: Five-Year Results of a Randomized Prospective Trial," Annals of Surgery, Vol. 241, No. 2, 2005, pp. 232-237. http://dx.doi.org/10.1097/01.sla.0000151892.35922.f2

[41] S. Kitano, N. Shiraishi, K. Fujii, K. Yasuda, M. Inomata and Y. Adachi, "A Randomized Controlled Trial Comparing Open vs Laparoscopy-Assisted Distal Gastrectomy for the Treatment of Early Gastric Cancer: An Interim Report," Surgery, Vol. 131, Suppl. 1, 2002, pp. S306S311. http://dx.doi.org/10.1067/msy.2002.120115

[42] J. H. Lee and H. S. Han, "A Prospective Randomized Study Comparing Open vs Laparoscopy-Assisted Distal Gastrectomy in Early Gastric Cancer: Early Results," Surgical Endoscopy And Other Interventional Techniques, Vol. 19, No. 2, 2005, pp. 168-173. http://dx.doi.org/10.1007/s00464-004-8808-y

[43] J. Cai, D. Wei, C. F. Gao, C. S. Zhang, H. Zhang and T. Zhao, "A Prospective Randomized Study Comparing Open versus Laparoscopy-Assisted D2 Radical Gastrectomy in Advanced Gastric Cancer," Digestive Surgery, Vol. 28, No. 5-6, 2011, pp. 331-337. http://dx.doi.org/10.1159/000330782
[44] H. H. Kim, W. J. Hyung, G. S. Cho, M. C. Kim, S. U. Han, W. Kim, S. W. Ryu, H. J. Lee and K. Y. Song, "Morbidity and Mortality of Laparoscopic Gastrectomy versus Open Gastrectomy for Gastric Cancer: An Interim Report-A Phase III Multicenter, Prospective, Randomized TRIAL (KLASS Trial)," Annals of Surgery, Vol. 251, No. 3, 2010, pp. 417-420. http://dx.doi.org/10.1097/SLA.0b013e3181cc8f6b

[45] H. Ohtani, Y. Tamamori, K. Noguchi, T. Azuma, S. Fujimoto, H. Oba, T. Aoki, M. Minami and K. Hirakawa, "A Meta-Analysis of Randomized Controlled Trials that Compared Laparoscopy-Assisted and Open Distal Gastrectomy for Early Gastric Cancer," Journal of Gastrointestinal Surgery, Vol. 14, No. 6, 2010, pp. 958-964. http://dx.doi.org/10.1007/s11605-010-1195-x

[46] J. Sun, J. Li, J. Wang, T. Pan, J. Zhou, X. Fu and S. Zhang, "Meta-Analysis of Randomized Controlled Trials on Laparoscopic Gastrectomy vs Open Gastrectomy for Distal Gastric Cancer," Hepatogastroenterology, Vol. 59, No. 118, 2012, pp. 1699-1705.

[47] K. Shehzad, K. Mohiuddin, S. Nizami, H. Sharma, I. M. Khan, B. Memon and M. A. Memon, "Current Status of Minimal Access Surgery for Gastric Cancer," Surgical Oncology, Vol. 16, No. 2, 2007, pp. 85-98.

http://dx.doi.org/10.1016/j.suronc.2007.04.012

[48] N. Shiraishi, K. Yasuda and S. Kitano, "Laparoscopic Gastrectomy with Lymph Node Dissection for Gastric Cancer," Gastric Cancer, Vol. 9, No. 3, 2006, pp. 167176. http://dx.doi.org/10.1007/s10120-006-0380-9

[49] H. H. Kim, S. U. Han, M. C. Kim, W. J. Hyung, W. Kim, H. J. Lee, S. W. Ryu, G. S. Cho, C. Y. Kim, H. K. Yang, J. Park do, K. Y. Song, S. I. Lee, S. Y. Ryu and J. H. Lee, "Prospective Randomized Controlled Trial (Phase III) to Comparing Laparoscopic Distal Gastrectomy with Open Distal Gastrectomy for Gastric Adenocarcinoma (KLASS 01)," Journal of the Korean Surgical Society, Vol. 84, No. 2, 2013, pp. 123-130. http://dx.doi.org/10.4174/jkss.2013.84.2.123

[50] K. Nakamura, H. Katai, J. Mizusawa, T. Yoshikawa, M. Ando, M. Terashima, S. Ito, M. Takagi, A. Takagane, M. Ninomiya, N. Fukushima and M. Sasako, "A Phase III Study of Laparoscopy-Assisted versus Open Distal Gastrectomy with Nodal Dissection for Clinical Stage IA/IB Gastric Cancer (JCOG0912)," Japanese Journal of Clinical Oncology, Vol. 43, No. 3, 2013, pp. 324-327. http://dx.doi.org/10.1093/jjco/hys220

[51] N. G. Coburn, "Improving Survival for Gastric Cancer Patients-The Role of the Surgeon," Journal of Clinical Oncology, Vol. 101, No. 2, 2010, pp. 103-104.

[52] K. Maruyama, M. Sasako, T. Kinoshita, T. Sano and H. Katai, "Surgical Treatment for Gastric Cancer: The Japanese Approach," Seminars in Oncology, Vol. 23, No. 3, 1996, pp. 360-368.

[53] J. Y. An, H. G. Youn, M. G. Choi, J. H. Noh, T. S. Sohn and S. Kim, "The Difficult Choice between Total and Proximal Gastrectomy in Proximal Early Gastric Cancer," The American Journal of Surgery, Vol. 196, No. 4, 2008, pp. 587-591.

http://dx.doi.org/10.1016/j.amjsurg.2007.09.040 
[54] F. Bozzetti, E. Marubini, G. Bonfanti, R. Miceli, C. Piano and L. Gennari, "Subtotal versus Total Gastrectomy for Gastric Cancer: Five-Year Survival Rates in a Multicenter Randomized Italian Trial. Italian Gastrointestinal Tumor Study Group," Annals of Surgery, Vol. 230, No. 2, 1999, pp. 170-178. http://dx.doi.org/10.1097/00000658-199908000-00006

[55] J. L. Gouzi, M. Huguier, P. L. Fagniez, B. Launois, Y. Flamant, F. Lacaine, J. C. Paquet and J. M. Hay, "Total versus Subtotal Gastrectomy for Adenocarcinoma of the Gastric Antrum. A French Prospective Controlled Study," Annals of Surgery, Vol. 209, No. 2, 1989, pp. 162-166. http://dx.doi.org/10.1097/00000658-198902000-00005

[56] S. H. Kim, M. S. Karpeh, D. S. Klimstra, D. Leung and M. F. Brennan, "Effect of Microscopic Resection Line Disease on Gastric Cancer Survival," Journal of Gastrointestinal Surgery, Vol. 3, No. 1, 1999, pp. 24-33. http://dx.doi.org/10.1016/S1091-255X(99)80004-3

[57] F. Bozzetti, G. Bonfanti, R. Bufalino, V. Menotti, S. Persano, S. Andreola, R. Doci and L. Gennari, "Adequacy of Margins of Resection in Gastrectomy for Cancer," Annals of Surgery, Vol. 196, No. 6, 1982, pp. 685-690. http://dx.doi.org/10.1097/00000658-198212001-00012

[58] H. R. Raziee, R. Cardoso, R. Seevaratnam, A. Mahar, L. Helyer, C. Law and N. Coburn, "Systematic Review of the Predictors of Positive Margins in Gastric Cancer Surgery and the Effect on Survival," Gastric Cancer, Vol. 15, Suppl. 1, 2011, pp. S116-S124.

[59] R. C. Martin Jr., D. P. Jaques, M. F. Brennan and M. Karpeh, "Extended Local Resection for Advanced Gastric Cancer: Increased Survival versus Increased Morbidity," Annals of Surgery, Vol. 236, No. 2, 2002, pp. 159-165. http://dx.doi.org/10.1097/00000658-200208000-00003

[60] J. D. Chen, X. P. Yang, J. G. Shen, W. X. Hu, X. M. Yuan and L. B. Wang, "Prognostic Improvement of Reexcision for Positive Resection Margins in Patients with Advanced Gastric Cancer," European Journal of Surgical Oncology, Vol. 39, No. 3, 2012, pp. 229-234. http://dx.doi.org/10.1016/j.ejso.2012.08.004

[61] M. Degiuli, M. Sasako, M. Calgaro, M. Garino, F. Rebecchi, M. Mineccia, D. Scaglione, D. Andreone, A. Ponti and F. Calvo, "Morbidity and Mortality after D1 and D2 Gastrectomy for Cancer: Interim Analysis of the Italian Gastric Cancer Study Group (IGCSG) Randomised Surgical Trial," European Journal of Surgical Oncology, Vol. 30, No. 3, 2004, pp. 303-308.

http://dx.doi.org/10.1016/j.ejso.2003.11.020

[62] F. Pacelli, G. B. Doglietto, R. Bellantone, S. Alfieri, A. Sgadari and F. Crucitti, "Extensive versus Limited Lymph Node Dissection for Gastric Cancer: A Comparative Study of 320 Patients," British Journal of Surgery, Vol. 80, No. 9, 1993, pp. 1153-1156. http://dx.doi.org/10.1002/bjs.1800800930

[63] A. Sierra, F. M. Regueira, J. L. Hernandez-Lizoain, F. Pardo, M. A. Martinez-Gonzalez and A. C. Javier, "Role of the Extended Lymphadenectomy in Gastric Cancer Surgery: Experience in a Single Institution," Annals of Surgical Oncology, Vol. 10, No. 3, 2003, pp. 219-226. http://dx.doi.org/10.1245/ASO.2003.07.009
[64] C. M. Volpe, J. Koo, S. M. Miloro, D. L. Driscoll, H. R. Nava and H. O. Douglass Jr., "The Effect of Extended Lymphadenectomy on Survival in Patients with Gastric Adenocarcinoma," Journal of the American College of Surgeons, Vol. 181, No. 1, 1995, pp. 56-64.

[65] J. J. Bonenkamp, I. Songun, J. Hermans, M. Sasako, K. Welvaart, J. T. Plukker, P. van Elk, H. Obertop, D. J. Gouma, C. W. Taat, et al., "Randomised Comparison of Morbidity after D1 and D2 Dissection for Gastric Cancer in 996 Dutch Patients," The Lancet, Vol. 345, No. 8952, 1995, pp. 745-748. http://dx.doi.org/10.1016/S0140-6736(95)90637-1

[66] A. Cuschieri, S. Weeden, J. Fielding, J. Bancewicz, J. Craven, V. Joypaul, M. Sydes and P. Fayers, "Patient Survival after D1 and D2 Resections for Gastric Cancer: Long-Term Results of the MRC Randomized Surgical Trial. Surgical Co-Operative Group," British Journal of Cancer, Vol. 79, No. 9-10, 1999, pp. 1522-1530. http://dx.doi.org/10.1038/sj.bjc.6690243

[67] I. Songun, H. Putter, E. M. Kranenbarg, M. Sasako and C. J. van de Velde, "Surgical Treatment of Gastric Cancer: 15-Year Follow-Up Results of the Randomised Nationwide Dutch D1D2 Trial," The Lancet Oncology, Vol. 11, No. 5, 2010, pp. 439-449. http://dx.doi.org/10.1016/S1470-2045(10)70070-X

[68] T. Sano, M. Sasako, S. Yamamoto, A. Nashimoto, A. Kurita, M. Hiratsuka, T. Tsujinaka, T. Kinoshita, K. Arai, Y. Yamamura and K. Okajima, "Gastric Cancer Surgery: Morbidity and Mortality Results from a Prospective Randomized Controlled Trial Comparing D2 and Extended Para-Aortic Lymphadenectomy_Japan Clinical Oncology Group Study 9501," Journal of Clinical Oncology, Vol. 22, No. 14, 2004, pp. 2767-2773. http://dx.doi.org/10.1200/JCO.2004.10.184

[69] M. Sasako, T. Sano, S. Yamamoto, Y. Kurokawa, A. Nashimoto, A. Kurita, M. Hiratsuka, T. Tsujinaka, T. Kinoshita, K. Arai, Y. Yamamura and K. Okajima, "D2 Lymphadenectomy Alone or with Para-Aortic Nodal Dissection for Gastric Cancer," The New England Journal of Medicine, Vol. 359, No. 5, 2008, pp. 453-462. http://dx.doi.org/10.1056/NEJMoa0707035

[70] N. N. Baxter and T. M. Tuttle, "Inadequacy of Lymph Node Staging in Gastric Cancer Patients: A PopulationBased Study," Annals of Surgical Oncology, Vol. 12, No. 12, 2005, pp. 981-987.

http://dx.doi.org/10.1245/ASO.2005.03.008

[71] N. G. Coburn, C. J. Swallow, A. Kiss and C. Law, "Significant Regional Variation in Adequacy of Lymph Node Assessment and Survival in Gastric Cancer," Cancer, Vol. 107, No. 9, 2006, pp. 2143-2151. http://dx.doi.org/10.1002/cncr.22229

[72] S. A. Hundahl, J. L. Phillips and H. R. Menck, "The National Cancer Data Base Report on Poor Survival of U.S. Gastric Carcinoma Patients Treated With Gastrectomy: Fifth Edition American Joint Committee on Cancer Staging, Proximal disease, and the 'Different Disease' Hypothesis," Cancer, Vol. 88, No. 4, 2000, pp. 921-932.

[73] K. C. Peeters, S. A. Hundahl, E. K. Kranenbarg, H. Hartgrink and C. J. van de Velde, "Low Maruyama Index 
Surgery for Gastric Cancer: Blinded Reanalysis of the Dutch D1-D2 Trial," World Journal of Surgery, Vol. 29, No. 12, 2005, pp. 1576-1584. http://dx.doi.org/10.1007/s00268-005-7907-9

[74] J. Fujita, Y. Kurokawa, T. Sugimoto, I. Miyashiro, S. Iijima, Y. Kimura, S. Takiguchi, Y. Fujiwara, M. Mori and Y. Doki, "Survival Benefit of Bursectomy in Patients with Resectable Gastric Cancer: Interim Analysis Results of a Randomized Controlled Trial," Gastric Cancer, Vol. 15, No. 1, 2012, pp. 42-48. http://dx.doi.org/10.1007/s10120-011-0058-9

[75] A. L. Mahar, N. G. Coburn, P. J. Karanicolas, R. Viola and L. K. Helyer, "Effective Palliation and Quality of Life Outcomes in Studies of Surgery for Advanced, NonCurative Gastric Cancer: A Systematic Review," Gastric Cancer, Vol. 15, Suppl. 1, 2011, pp. S138-S145.

[76] A. L. Mahar, N. G. Coburn, S. Singh, C. Law and L. K. Helyer, "A Systematic Review of Surgery for Non-Curative Gastric Cancer," Gastric Cancer, Vol. 15, Suppl. 1, 2012, pp. S125-S137.

[77] K. Fujitani, H. K. Yang, Y. Kurokawa, J. Park do, T. Tsujinaka, B. J. Park, H. Fukuda, S. H. Noh, N. Boku, Y. J. Bang, M. Sasako and J. I. Lee, "Randomized Controlled Trial Comparing Gastrectomy plus Chemotherapy with Chemotherapy Alone in Advanced Gastric Cancer with a Single Non-Curable Factor: Japan Clinical Oncology Group Study JCOG 0705 and Korea Gastric Cancer Association Study KGCA01," Japanese Journal of Clinical Oncology, Vol. 38, No. 7, 2008, pp. 504-506. http://dx.doi.org/10.1093/jjco/hyn058

[78] S. P. Kerkar, C. D. Kemp, A. Duffy, U. S. Kammula, D. S. Schrump, K. F. Kwong, M. Quezado, B. R. Goldspiel, A. Venkatesan, A. Berger, M. Walker, M. A. Toomey, S. M. Steinberg, G. Giaccone, S. A. Rosenberg and I. Avital, "The GYMSSA Trial: A Prospective Randomized Trial Comparing Gastrectomy, Metastasectomy plus Systemic Therapy versus Systemic Therapy Alone," Trials, Vol. 10, No. 121, 2009, p. 121.

[79] R. Swan and T. J. Miner, "Current Role of Surgical Therapy in Gastric Cancer," World Journal of Gastroenterology, Vol. 12, No. 3, 2006, pp. 372-379.

[80] J. S. Macdonald, "Gastric Cancer-New Therapeutic Options," The New England Journal of Medicine, Vol. 355, No. 1, 2006, pp. 76-77.

\section{http://dx.doi.org/10.1056/NEJMe068121}

[81] J. S. Macdonald, S. R. Smalley, J. Benedetti, S. A. Hundahl, N. C. Estes, G. N. Stemmermann, D. G. Haller, J. A. Ajani, L. L. Gunderson, J. M. Jessup and J. A. Martenson, "Chemoradiotherapy after Surgery Compared with Surgery Alone for Adenocarcinoma of the Stomach or Gastroesophageal Junction," The New England Journal of Medicine, Vol. 345, No. 10, 2001, pp. 725-730. http://dx.doi.org/10.1056/NEJMoa010187

[82] D. Cunningham, W. H. Allum, S. P. Stenning, J. N. Thompson, C. J. Van de Velde, M. Nicolson, J. H. Scarffe, F. J. Lofts, S. J. Falk, T. J. Iveson, D. B. Smith, R. E. Langley, M. Verma, S. Weeden, Y. J. Chua and M. T. Participants, "Perioperative Chemotherapy versus Surgery Alone for Resectable Gastroesophageal Cancer," The New England Journal of Medicine, Vol. 355, No. 1, 2006, pp. 11-20. http://dx.doi.org/10.1056/NEJMoa055531

[83] X. Paoletti, K. Oba, T. Burzykowski, S. Michiels, Y. Ohashi, J. P. Pignon, P. Rougier, J. Sakamoto, D. Sargent, M. Sasako, E. Van Cutsem and M. Buyse, "Benefit of Adjuvant Chemotherapy for Resectable Gastric Cancer: A Meta-Analysis," The Journal of the American Medical Association, Vol. 303, No. 17, 2010, pp. 1729-1737. http://dx.doi.org/10.1001/jama.2010.534

[84] D. Takahari, T. Hamaguchi, K. Yoshimura, H. Katai, S. Ito, N. Fuse, M. Konishi, H. Yasui, M. Terashima, M. Goto, N. Tanigawa, K. Shirao, T. Sano and M. Sasako, "Survival Analysis of Adjuvant Chemotherapy with S-1 plus Cisplatin for Stage III Gastric Cancer," Gastric Cancer, Epub Ahead of Print, 2013.

[85] Y. J. Bang, Y. W. Kim, H. K. Yang, H. C. Chung, Y. K. Park, K. H. Lee, K. W. Lee, Y. H. Kim, S. I. Noh, J. Y. Cho, Y. J. Mok, J. Ji, T. S. Yeh, P. Button, F. Sirzen and S. H. Noh, "Adjuvant Capecitabine and Oxaliplatin for Gastric Cancer after D2 Gastrectomy (CLASSIC): A Phase 3 Open-Label, Randomised Controlled Trial," The Lancet, Vol. 379, No. 9813, 2012, pp. 315-321. http://dx.doi.org/10.1016/S0140-6736(11)61873-4

[86] T. Sano, "Adjuvant and Neoadjuvant Therapy of Gastric Cancer: A Comparison of Three Pivotal Studies," Current Oncology Reports, Vol. 10, No. 3, 2008, pp. 191-198. http://dx.doi.org/10.1007/s11912-008-0030-y 